\title{
Usefulness of pulsed-field gel electrophoresis in tracking two outbreaks of invasive meningococcal disease serogroup $C$ in British Columbia
}

\author{
Grahame Quan ${ }^{1,2}$, Mark Gilbert MD MHSc FRCPC 1,2 , Samara T David MHSc ${ }^{2,3}$, Tazim Rahim BSc ${ }^{2}$, Kathy Adie BSc ${ }^{2}$, \\ Carol Shaw MSc ${ }^{2}$, Alan McNabb BSc ART ${ }^{2}$, Judy Isaac-Renton MD DPH FRCPC ${ }^{1,2}$, David M Patrick MD FRCPC MHSC ${ }^{1,2}$
}

G Quan, M Gilbert, ST David, et al. Usefulness of pulsed-field gel electrophoresis in tracking two outbreaks of invasive meningococcal disease serogroup $\mathrm{C}$ in British Columbia. Can J Infect Dis Med Microbiol 2007;18(6):363-367.

Two major outbreaks of invasive meningococcal disease serogroup C (IMD-C) were identified in British Columbia between 2000 and 2004. Pulsed-field gel electrophoresis (PFGE) and porA gene sequencing of all retained IMD-C isolates were used to assess correlations between genotypes and epidemiological patterns. PFGE patterns of IMD-C genotypes correlated with epidemiological patterns between 2000 and 2004 in British Columbia, and demonstrated that PFGE can identify outbreakrelated cases. Both IMD-C outbreaks correlated with a respective PFGE pattern. PFGE analysis demonstrated that the 2004 British Columbia outbreak strain in men who have sex with men was closely related to the 2001 Abbotsford outbreak strain. PorA sequencing data indicated low diversity of class 1 outer membrane proteins in British Columbia, and did not correlate with epidemiological trends. There was a trend for outbreak-associated PFGE types to demonstrate higher case fatality rates.

Key Words: Epidemiology; Gel electrophoresis; Molecular; Neisseria meningitidis; PorA protein; Pulsed-field; Serogroup C

T he interpretation of restriction patterns of chromosomal DNA by pulsed-field gel electrophoresis (PFGE) can be used to assess the genetic relatedness of bacterial strains, and has been used to distinguish sporadic strains from outbreak strains of Neisseria meningitidis (1-5). Such information aids in the process of identifying and containing outbreaks of invasive meningococcal disease.

The diversity of the porA gene may be a potential epidemiological marker during outbreaks of meningococcal disease (6). The por A gene of $N$ meningitidis encodes the class 1 outer membrane protein, a prospective vaccine target, which has been characterized by serosubtype. There are several genetic events that enable hindrance of epitope recognition by bactericidal antibodies or nonexpression of the por $\mathrm{A}$ gene. Nonserosubtypeable por $\mathrm{A}$ variants and nonexpressed por $\mathrm{A}$ genes are relatively rare, but can also be characterized by nucleotide sequence analysis (7).

Since January 2000, two outbreaks of invasive meningococcal disease serogroup C (IMD-C) were identified in British Columbia (BC) (Table 1). In 2000/2001, an outbreak was identified in Abbotsford, BC. In the first wave of this outbreak, cases occurred primarily among teenagers and young adults (8), while in the second wave, the outbreak cases were older,

\section{Utilité de l'électrophorèse en champ pulsé pour retracer deux éclosions d'infection invasive à méningocoque du groupe $\mathrm{C}$ en Colombie-Britannique}

\begin{abstract}
Deux éclosions majeures d'infection invasive à méningocoque du groupe $\mathrm{C}$ (IIM-C) ont été identifiés en Colombie-Britannique entre 2000 et 2004. Lélectrophorèse en champ pulsé (ÉCP) et le séquençage du gène porA de tous les isolats d'IIM-C conservés ont été utilisés pour évaluer les corrélations entre les génotypes et les tableaux épidémiologiques. Les résultats de l'ÉCP pour les génotypes d'IIM-C ont été en corrélation avec les tableaux épidémiologiques entre 2000 et 2004 en ColombieBritannique et ont confirmé que l'ÉGP permet d'identifier les cas liés à des éclosions. Les deux éclosions d'IIM-C ont été en corrélation avec un tableau respectif d'ÉCP. L'analyse par ÉCP a démontré que la souche responsable de l'éclosion de 2004 en Colombie-Britannique chez des hommes ayant eu des relations sexuelles avec d'autres hommes était étroitement liée à la souche responsable de l'éclosion de 2001 à Abbotsford. Ces données de séquençage du gène porA ont indiqué une faible diversité des protéines de la membrane externe de classe 1 en Colombie-Britannique et n'ont pas été en corrélation avec les tendances épidémiologiques. Les types d'ÉCP associés aux éclosions ont eu tendance à s'accompagner d'un taux de mortalité plus élevé.
\end{abstract}

\begin{tabular}{|c|c|c|c|c|c|}
\hline $\begin{array}{l}\text { Outbreak } \\
\text { number }\end{array}$ & $\begin{array}{l}\text { Outbreak } \\
\text { period }\end{array}$ & Case definition & $\begin{array}{c}\text { Cases } \\
\text { (n) }\end{array}$ & $\begin{array}{l}\text { Deaths } \\
\text { n (\%) }\end{array}$ & $\begin{array}{l}\text { Isolates } \\
\text { available } \\
\text { (\%) }\end{array}$ \\
\hline $1 a$ & $\begin{array}{c}\text { Dec } 2000 \text { to } \\
\text { Mar } 2001\end{array}$ & $\begin{array}{l}\text { IMD-C and residents } \\
\text { of Abbotsford, BC, or } \\
\text { the surrounding area, } \\
\text { who are between } 13 \\
\text { and } 29 \text { years of age }\end{array}$ & 5 & $2(40)$ & $3(60)$ \\
\hline $1 b$ & $\begin{array}{l}\text { Oct } 2001 \text { to } \\
\text { Dec } 2001\end{array}$ & $\begin{array}{l}\text { IMD-C and residents of } \\
\text { Abbotsford or the } \\
\text { surrounding area; } \\
\text { street-involved or close } \\
\text { contact with street- } \\
\text { involved persons }\end{array}$ & 4 & $3(75)$ & $4(100)$ \\
\hline 2 & $\begin{array}{l}\text { Sept } 2004 \text { to } \\
\text { Dec } 2004\end{array}$ & $\begin{array}{l}\text { IMD-C and male in BC; } \\
\text { identified as MSM (sexual } \\
\text { activity with male partner } \\
\text { and/or self-identification } \\
\text { as a gay men) }\end{array}$ & ${ }^{7}$ & $5(71)$ & $5(71)$ \\
\hline
\end{tabular}

Dec December; Mar March; MSM Men who have sex with men; Oct October; Sept September

${ }^{1}$ University of British Columbia; ${ }^{2}$ British Columbia Centre for Disease Control, Vancouver, British Columbia; ${ }^{3}$ Canadian Field Epidemiology

Program, Public Health Agency of Canada, Ottawa, Ontario

Correspondence and reprints: Dr David M Patrick, British Columbia Centre for Disease Control, 655 West 12th Avenue, Vancouver,

British Columbia V5Z 4R4. Telephone 604-660-3199, fax 604-660-0197, e-mail David.Patrick@bccdc.ca

Received for publication April 2, 2007. Accepted September 5, 2007 


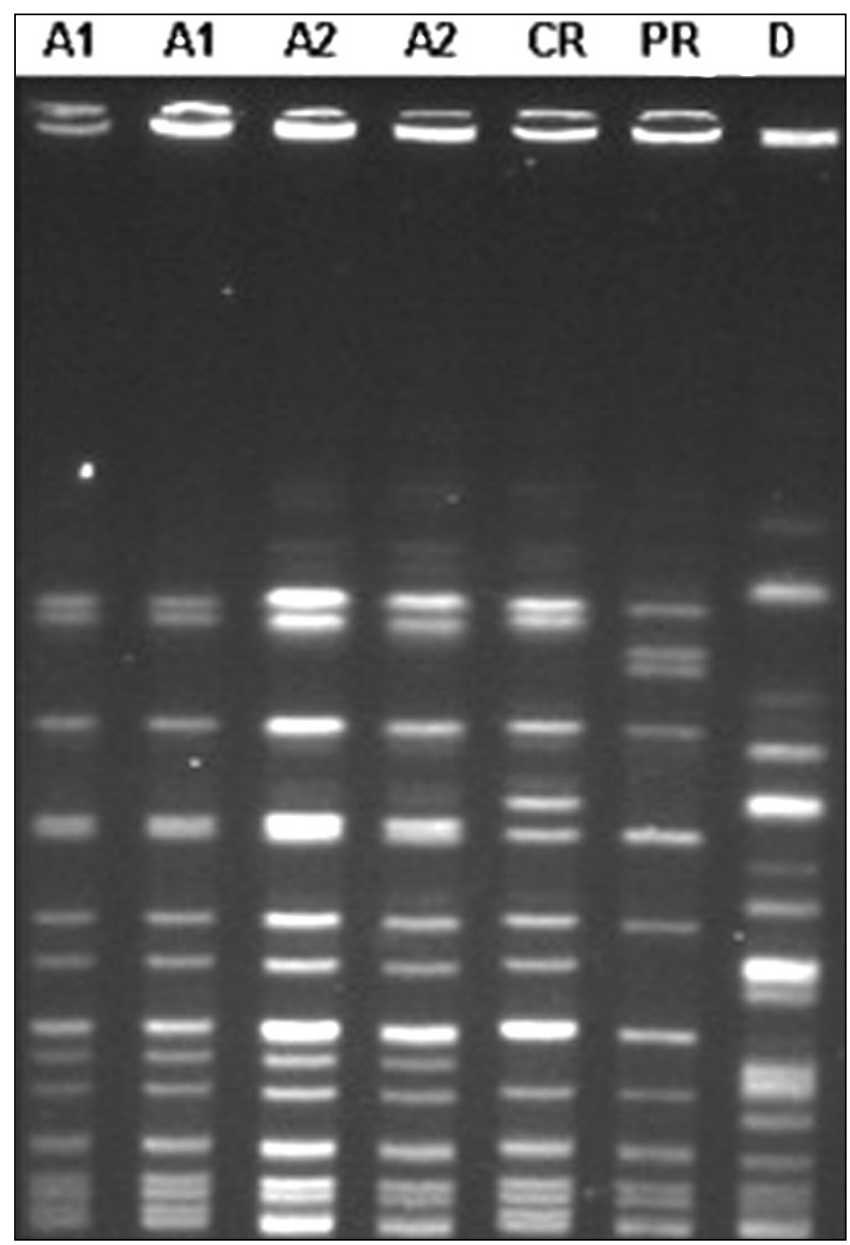

Figure 1) Pulsed-field gel electrophoresis patterns of invasive Neisseria meningitidis serogroup C isolates in British Columbia between 2000 and 2004. Clustering of isolates was conducted following Tenover et al's (5) criteria. Compared with the A1 strain (2001 outbreak): Closely related (CR) isolates differed by one to three fragments, possibly related (PR) isolates differed by four to six fragments and different $(D)$ isolates differed by seven or more fragments. A2 (2004 outbreak) is a subset of the CR patterns. Control strains of $\mathrm{A} 1$ and $\mathrm{A} 2$ pattern types plus a Salmonella branderup standard strain were run on each gel for comparison

and had either a direct or an indirect connection to the 'streetinvolved' population (9). In 2004, a second outbreak in BC was identified among men who have sex with men (MSM) (10).

Few longitudinal molecular studies on IMD-C have been performed in BC. The present molecular epidemiological study was performed of all IMD-C isolates found in BC between January 2000 and December 2004. PFGE and porA gene sequencing were used to determine whether the genotype correlated with the epidemiological pattern of IMD-C outbreaks during this five-year period. The present study sought to determine the degree of genetic relatedness of invasive cases between the Abbotsford outbreak and the MSM outbreak, as well as with sporadic cases. Finally, it examined whether there was an association between PFGE or porA gene sequences and case fatality rates.

\section{METHODS}

Laboratory methods

All $\mathrm{N}$ meningitidis serogroup $\mathrm{C}$ cultures analyzed were from available isolates obtained from IMD-C cases ( $\mathrm{n}=55 ; 12$ outbreakrelated and 43 sporadic) in BC between January 1, 2000, and
December 31, 2004. Isolates were collected and stored at the British Columbia Centre for Disease Control at a temperature of $-70^{\circ} \mathrm{C}$.

PFGE testing: A modification of a National Microbiology Laboratory protocol was used, in which isolates were subjected to PFGE after digestion by SpeI restriction enzyme following a method previously described (8). Relatedness of PFGE patterns was evaluated visually according to criteria established by Tenover et al (5). According to these criteria, PFGE patterns were assigned to one of four categories - indistinguishable, closely related, possibly related and unrelated. Closely related strains differ from outbreak strains by changes consistent with a single genetic event, which is represented by a difference of two to three fragments in the PFGE pattern. Possibly related strains differ by two genetic events, represented by a four- to six-fragment difference, and unrelated strains differ by threeor more genetic events, represented by a seven- or more fragment difference.

porA sequencing: Sequences were determined using an $\mathrm{ABI}$ Prism 3100 genetic analyzer (Applied Biosystems, USA) and ABI Prism BigDye terminator cycle sequencing ready reaction kit (version 3.1; Applied Biosystems), following the manufacturer's instructions. The primers used for polymerase chain reaction (PCR) amplification were 210 and 211 (11). The primers used for sequencing were 210, 211 and 122L, 122U, 103L and 103U (12). PCR: Diagnosis of meningococcal disease and identification of serogroup $\mathrm{C}$ were performed at the microbiology laboratory at BC Children's Hospital (Vancouver, BC) by PCR in methods previously described (13).

\section{Epidemiological methods}

In $\mathrm{BC}$, invasive meningococcal disease is reportable; regional public health staff enter reports into a provincial database (ie, demographic information, disease type and symptom onset). In addition, enhanced surveillance is conducted through the completion of a case report form, which is returned to the British Columbia Centre for Disease Control. This form includes information on clinical presentation and outcome, risk factors for infection and preliminary laboratory testing.

During outbreaks, cases were identified from these surveillance databases and from discussions with regional public health staff. A case of IMD-C is defined as an individual who has $\mathrm{N}$ meningitidis serogroup $\mathrm{C}$ isolated from a normally sterile site (eg, blood or cerebrospinal fluid). Additional epidemiological characteristics used to define cases in each outbreak are presented in Table 1 .

\section{Analysis}

EpiData, version 3.0 (EpiData Association, Denmark), was used to create a database for integrating surveillance and laboratory data. Data were exported to Epi Info 6, version 6.04 (Centers for Disease Control and Prevention, USA), for analysis. Proportions were compared using the $\chi^{2}$ test with a 0.05 significance level.

\section{RESULTS}

The two most frequent IMD-C PFGE patterns of all isolates collected in BC identified between 2001 and 2004 differed from one another by a single genetic event, represented by a two-fragment difference, and were considered to be closely related (Figure 1 ). These strains were arbitrarily named A1 and A2. Pattern A1 was the most frequent pattern in 2001 (seven 


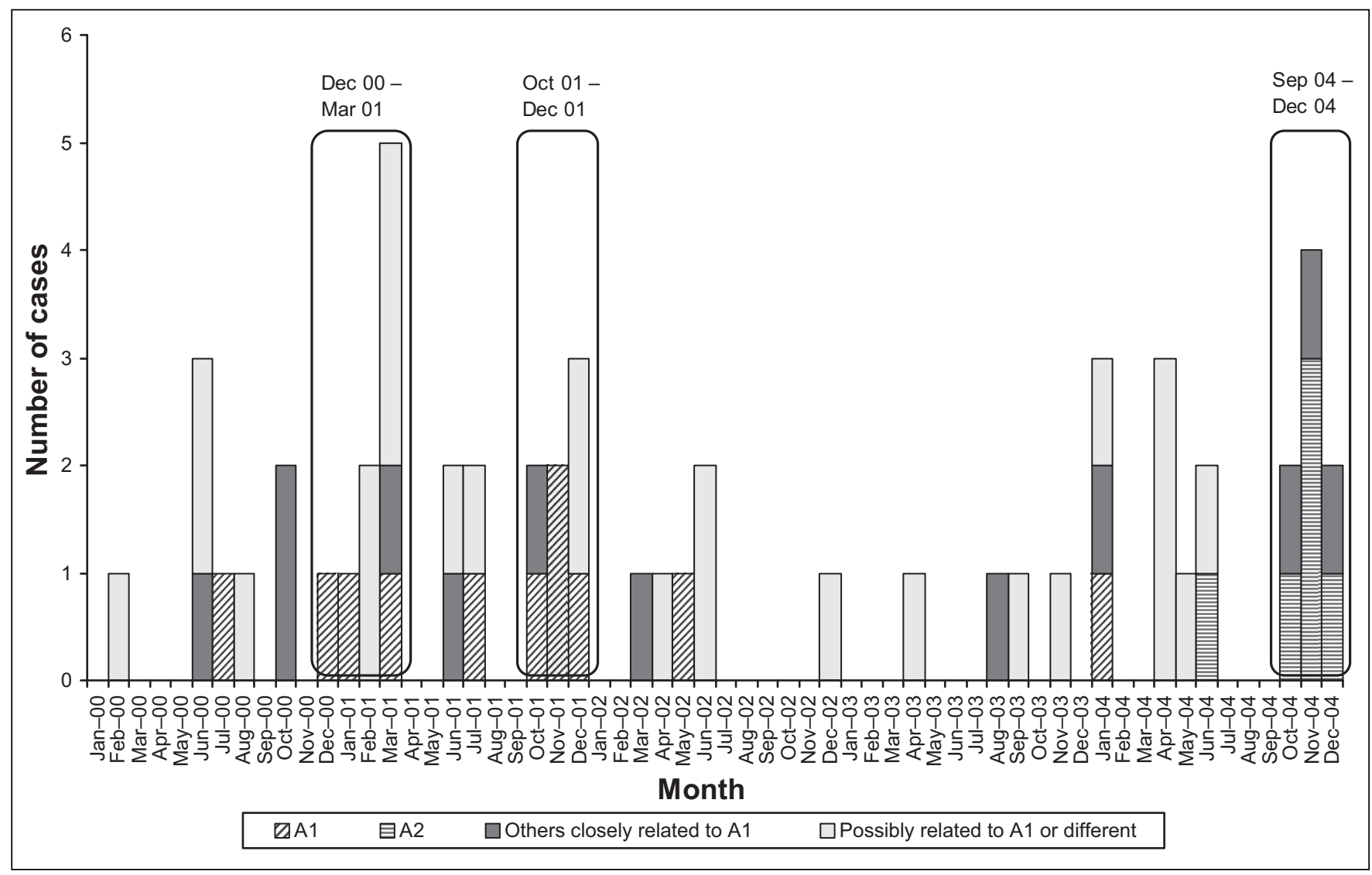

Figure 2) Invasive meningococcal C pulsed-field gel electrophoresis patterns by month in British Columbia between 2000 and 2004. Apr April; Aug August; Dec December; Feb February; Jan January; Jul July; Jun June; Mar March; Nov November; Oct October; Sep September

TABLE 2

Invasive meningococcal C pulsed-field gel electrophoresis patterns associated with outbreak periods

\begin{tabular}{|c|c|c|c|c|c|}
\hline & \multirow{2}{*}{$\begin{array}{c}\text { Isolates from } \\
\text { outbreak periods/ } \\
\text { total isolates, } \\
2000-2004^{*} \\
n(\%)\end{array}$} & \multirow{2}{*}{$\begin{array}{c}\text { Isolates from } \\
\text { nonoutbreak periods/ } \\
\text { total isolates, } \\
2000-2004^{*} \\
\mathrm{n}(\%)\end{array}$} & \multicolumn{3}{|c|}{ Outbreak-associated isolates/total isolates during outbreak periods } \\
\hline & & & $\begin{array}{c}\text { Outbreak 1a, } 2001 \\
\text { n (\%) }\end{array}$ & $\begin{array}{c}\text { Outbreak 1b, } 2001 \\
n(\%)\end{array}$ & $\begin{array}{c}\text { Outbreak 2, } 2004 \\
\text { n (\%) }\end{array}$ \\
\hline A1 & $7 / 11(64)$ & $4 / 11(36)$ & $3 / 3(100)$ & $4 / 4(100)$ & $0 / 0(0)$ \\
\hline A2 & $5 / 6(83)$ & $1 / 6(17)$ & $0 / 0(0)$ & $0 / 0(0)$ & $3 / 5(60)$ \\
\hline Others closely related to $\mathrm{A} 1$ & $5 / 12(42)$ & $7 / 12(58)$ & $0 / 1(0)$ & $0 / 1(0)$ & $2 / 3(67)$ \\
\hline
\end{tabular}

*Distribution of pulsed-field gel electrophoresis patterns differs significantly during outbreak and nonoutbreak periods $\left(\chi^{2}=8.61, P=0.035\right)$

of 19 cases [37\%] in 2001) (Figure 2, Table 2). Pattern A2 was first identified in 2004 and was the most frequent PFGE pattern in that year (six of 17 cases [35\%] in 2004). The difference in proportion of isolates by PFGE pattern between 2001 and 2004 was statistically significant $\left(\chi^{2}=11.17, \mathrm{P}=0.01\right)$. In 2002 and 2003, there were few cases overall, with only one A1 case in 2002 and no A1 cases in 2003 (Figure 2).

\section{Abbotsford outbreaks}

All cases with isolates available for testing had the A1 pattern between December 2000 and March 2001 (three of three), and between October 2001 and December 2001 (four of four) (Table 2). Two of the December 2000 to March 2001 cases that fit the epidemiological case definitions were identified as IMD-C by PCR. No isolates were obtained for these two cases, thus,
PFGE and por A sequencing could not be completed. All nine of the non-A1 patterns from this period were from patients that were not identified as cases in the outbreak (Table 2).

\section{MSM outbreak}

During the MSM outbreak period, eight isolates with MSM data and PFGE results were available for comparison. Of the five cases identified as MSM, three (60\%) had the A2 PFGE pattern and two (40\%) were closely related to A2 (Table 2). The two 'non-MSM' A2 cases were male and were associated with travel to or residence in Vancouver or the lower mainland. No A1 patterns were identified during the MSM outbreak period. Two MSM cases were confirmed as having IMD-C by PCR; isolates were not available for further molecular testing. 
TABLE 3

Case fatality rate* for invasive meningococcal $C$ cases with known outcomes by pulsed-field gel electrophoresis pattern between 2000 and 2004

\begin{tabular}{lcccc}
\hline $\begin{array}{l}\text { Pulsed-field gel } \\
\text { electrophoresis }\end{array}$ & $\begin{array}{c}\text { Died } \\
(\mathbf{n})\end{array}$ & $\begin{array}{c}\text { Survived } \\
(\mathbf{n})\end{array}$ & $\begin{array}{c}\text { Total } \\
(\mathbf{n})\end{array}$ & Rate (\%) \\
\hline A1 & 5 & 4 & 9 & 56 \\
A2 & 2 & 3 & 5 & 40 \\
Others closely related to A1 & 3 & 8 & 11 & 27 \\
Possibly related to A1 or different & 4 & 17 & 21 & 19 \\
A1 and all closely related to A1 & 10 & 15 & 25 & 40 \\
\hline
\end{tabular}

${ }^{*}$ Not statistically significant $\left(\chi^{2}=4.237, P=0.237\right)$

Outbreak strains

There was an association between A1 and A2 PFGE patterns during outbreak periods (seven of 11 [64\%] and five of six [83\%], respectively; Table 2). In contrast, only seven of 26 (27\%) possibly related to A1 or different PFGE patterns were associated with outbreak periods $\left(\chi^{2}=8.61, \mathrm{P}=0.04\right)$. Figure 2 shows that the $\mathrm{A} 1$ and $\mathrm{A} 2$ patterns were associated with the outbreak periods in 2001 and 2004.

\section{Case fatality by strain}

There was a trend toward IMD-C cases with A1 or A2 and closely related PFGE patterns having a higher case fatality rate (40\%) compared with cases with PFGE patterns that were possibly related to A1 or different (19\%) (Table 3). Due to the small number of cases analyzed, this trend was not statistically significant.

\section{PorA gene analysis}

Among the por A gene sequences, there were two major clusters and several small clusters (Figure 3; the GenBank accession numbers of the $N$ meningitidis por $\mathrm{A}$ sequences are DQ403960 to DQ404009). No correlations were found among the porA clusters and outbreak periods, case fatality rates or any other epidemiological patterns (data not shown). There was no association found between por $\mathrm{A}$ gene sequences and PFGE patterns.

\section{DISCUSSION}

We observed a strong correlation between PFGE results and epidemiological data. The A1 and A2 PFGE patterns were linked with the respective 2001 and 2004 IMD-C outbreaks in BC. Epidemics were generally clonal and consistent with our findings for Abbotsford, because all epidemiologically defined cases had the A1 pattern during both outbreak waves in 2000/2001.

Based on PFGE clustering analysis, the MSM outbreak strain of 2004 was closely related to the Abbotsford outbreak strain of 2001. However, there was more than one PFGE pattern among the MSM outbreak strains. The dominant strain was A2, but there were also two other closely related strains identified in the MSM cases. These closely related strains were likely part of the same clonal outbreak because each differed by a single genetic event (5). Two recent MSM-confirmed IMD-C cases in 2005 (three and four months after 2004 outbreak period) were analyzed by PFGE and both were non-A2 (data not shown). One case was closely related to $\mathrm{A} 2$ and the other was possibly related. In a large epidemiological window, early cases would be expected to have low diversity, whereas later cases would have increased opportunity for random genetic changes (14).

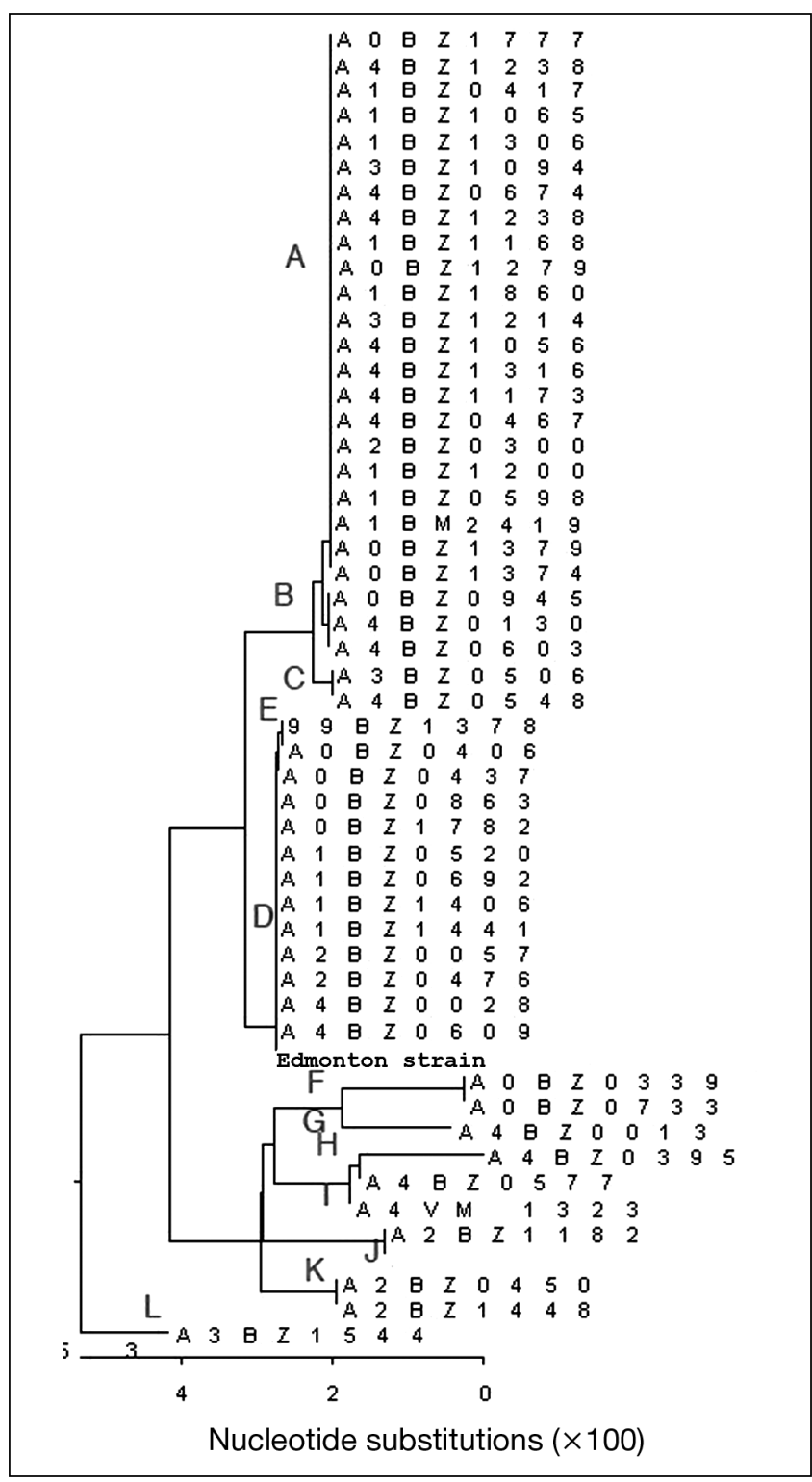

Figure 3) Dendrogram of porA identical gene sequence clusters. Each cluster is composed of identical sequences (*AOBZ1729 in cluster A differed by a single nucleotide). Year of isolate sequences is denoted by the second digit in the serial number (eg, A4BZ $x x x x$ indicates an isolate from 2004). porA sequence clusters did not distinguish any epidemiological patterns or outbreak and nonoutbreak periods

To date, there has been a paucity of literature on whether there is enough genetic variability among meningococci to make Tenover et al's criteria applicable for this organism. The strong correlation of PFGE results and epidemiological data observed in the present study validates using PFGE genetic characterization of IMD-C as a molecular tool to track outbreaks while they are still underway. The PFGE data for Abbotsford was stronger than the MSM PFGE data, because all Abbotsford outbreak cases were a single PFGE pattern. An interesting note is that three of the 2004 A2 cases (two during the second outbreak period) were male, but they were not identified during routine public health follow-up as MSM. It is possible that one or more of these cases were, in fact, MSM; survivors may be unwilling to disclose this information to public health officials, or family members may be unaware of this history. Requestioning of these 
cases or their families regarding sexual orientation following PFGE pattern testing was not performed. The present study suggests that during an outbreak investigation, PFGE and other molecular methods may prove to be a useful adjunct to public health follow-up in discovering epidemiological connections and identifying cases in marginalized populations.

Epidemiologically, the trend of IMD-C cases with A1 or A2 and closely related PFGE patterns having a higher case $(40 \%)$ fatality rate in comparison with possibly related or different PFGE (19\%) (Table 3) indicates that the A1, A2 and closely related genotypes may represent more virulent variants, which could contribute to higher mortality rates. This hypothesis, however, is based on low isolate numbers; no virulence mechanism has been identified. A study (15) in Spain comparing clinical and carrier meningococcal $\mathrm{C}$ isolates suggested that PFGE may be able to distinguish more virulent strains and that using several separate endonucleases may actually increase the discriminatory power. Further studies are required to examine this possibility of increased virulence in the A1 and A2 PFGE genotypes.

Unlike PFGE testing, the porA gene sequences did not distinguish strains in any association with epidemiological patterns. In contrast to the findings of Jelfs et al (6), our data indicated that the por A diversity in $\mathrm{BC}$ was quite low and was dominated by two main sequence clusters (Figure 3 ). It has been suggested that genetic fingerprint patterns (eg, PFGE) are independent of variable antigens (such as porA proteins),

\section{REFERENCES}

1. McEllistrem MC, Kolano JA, Pass MA, et al. Correlating epidemiologic trends with the genotypes causing meningococcal disease, Maryland; Maryland Emerging Infections Program. Emerg Infect Dis 2004;10:451-6.

2. Finn R, Groves C, Coe M, Pass M, Harrison LH. Cluster of serogroup $\mathrm{C}$ meningococcal disease associated with attendance at a party. South Med J 2001;94:1192-4.

3. Edmond MB, Hollis RJ, Houston AK, Wenzel RP. Molecular epidemiology of an outbreak of meningococcal disease in a university community. J Clin Microbiol 1995;33:2209-11.

4. Popovic T, Schmink S, Rosenstein NA, et al. Evaluation of pulsed-field gel electrophoresis in epidemiological investigations of meningococcal disease outbreaks caused by Neisseria meningitidis serogroup C. J Clin Microbiol 2001;39:75-85.

5. Tenover FC, Arbeit RD, Goering RV, et al. Interpreting chromosomal DNA restriction patterns produced by pulsed-field gel electrophoresis: Criteria for bacterial strain typing. J Clin Microbiol 1995;33:2233-9.

6. Jelfs J, Munro R, Wedege E, Caugant DA. Sequence variation in the porA gene of a clone of Neisseria meningitidis during epidemic spread. Clin Diagn Lab Immunol 2000;7:390-5.

7. Russell JE, Jolley KA, Feavers IM, Maiden MC, Suker J. PorA variable regions of Neisseria meningitidis. Emerg Infect Dis 2004;10:674-8

8. Patrick DM, Champagne S, Goh SH, et al. Neisseria meningitidis carriage during an outbreak of serogroup C disease. Clin Infect Dis $2003 ; 37: 1183-8$ which may change at a faster rate due to selective pressure, such as evading immune defense (15). In addition, single gene changes affect only a small part of the chromosome and these changes may not affect the degree of genetic relatedness between strains (16). Our data indicated that porA clusters identified in BC between 2000 and 2004 were not an appropriate neutral marker to measure genetic relatedness of strains compared with PFGE, which reflected a fingerprint of the entire chromosome and allowed clustering of outbreak strains.

The present study demonstrated that PFGE testing can cluster outbreak-related cases and is a useful tool in outbreak investigations. PorA sequencing data indicated low diversity in $\mathrm{BC}$ and did not correlate with epidemiological trends. The trend of IMD-C cases with outbreak-associated strains having higher case fatality rates suggests that these strains may be linked with virulence factors. Additional studies to investigate this hypothesis are required.

ACKNOWLEDGEMENTS: Mr Quan was funded by the Canadian Institutes for Health Research Translational Research in Infectious Disease Program at the University of British Columbia. The authors thank Raymond Tsang and the National Microbiology Laboratory, Health Canada, for their assistance with the present study.

CONFLICTS OF INTEREST: The authors declare no conflicts of interest.

9. Bigham M, Trepanier MJ, Dobson S. Meningococcal disease in British Columbia - 2001 summary. <http://www.bccdc.org/ downloads/pdf/epid/reports/meningo_summary_2001.pdf? PHPSESSID=03a2887b3ea965ef6efc9307> (Version current at September 28, 2007).

10. Gilbert M, David ST, Pass M, et al. New cases of meningococcal group C infections in gay men in BC. BC Med J 2005;47:228.

11. Feavers IM, Maiden MC. A gonococcal porA pseudogene: Implications for understanding the evolution and pathogenicity of Neisseria gonorrhoeae. Mol Microbiol 1998;30:647-56.

12. Suker J, Feavers IM, Achtman M, Morelli G, Wang JF, Maiden MC. The porA gene in serogroup A meningococci: Evolutionary stability and mechanism of genetic variation. Mol Microbiol 1994;12:253-65.

13. Pollard AJ, Bigham M, Shaw E, et al. Meningococcal disease in British Columbia. BC Med J 2001;43:21-7.

14. Goering RV, Tenover FC. Epidemiological interpretation of chromosomal macro-restriction fragment patterns analyzed by pulsed-field gel electrophoresis. J Clin Microb 1997;35:2432-3.

15. Arreaza L, Berron S, Fernandez S, Santiago MI, Malvar A, Vazquez JA. Investigation for a more virulent variant among the c:2b:P1.2,5 Spanish meningococcal epidemic strains by molecular epidemiology. J Med Microbiol 2000;49:1079-84.

16. Malorny B, Maiden MC, Achtman M. The porA alleles are identical in subgroup III serogroup A Neisseria meningitidis strains isolated in China in the 1960s and 1980s. J Clin Microbiol 1996;34:1548-50. 


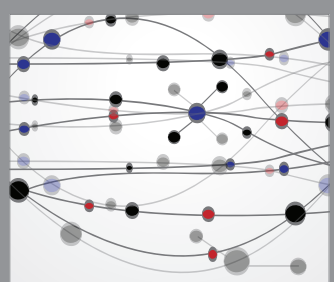

The Scientific World Journal
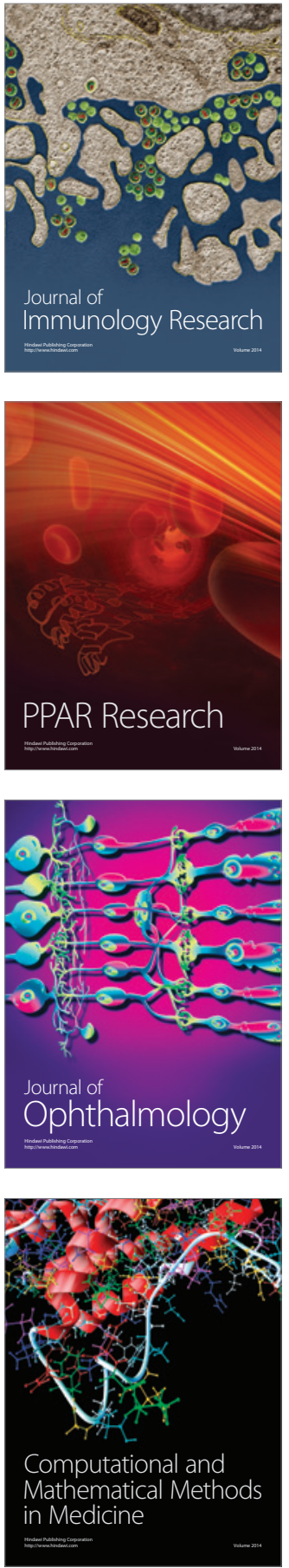

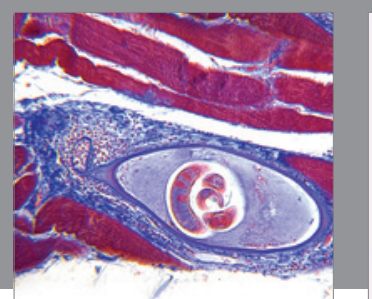

Gastroenterology Research and Practice

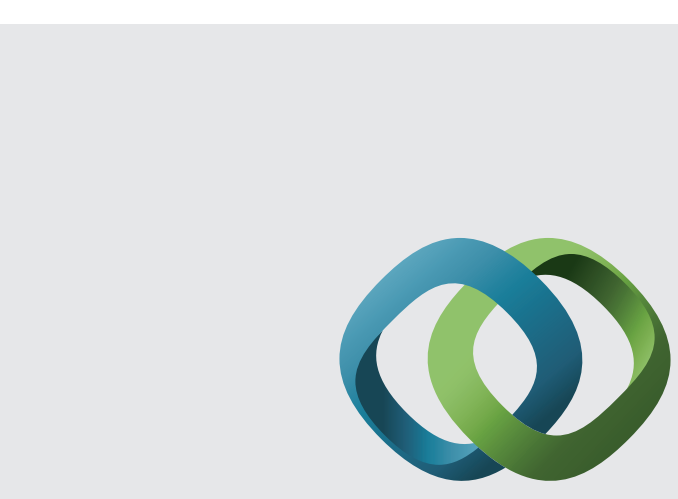

\section{Hindawi}

Submit your manuscripts at

http://www.hindawi.com
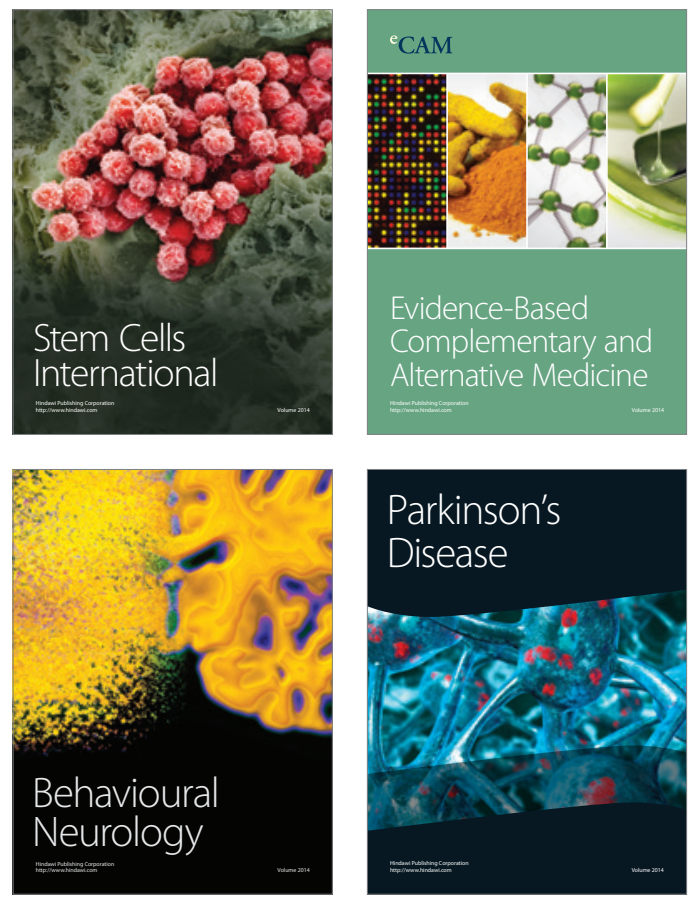
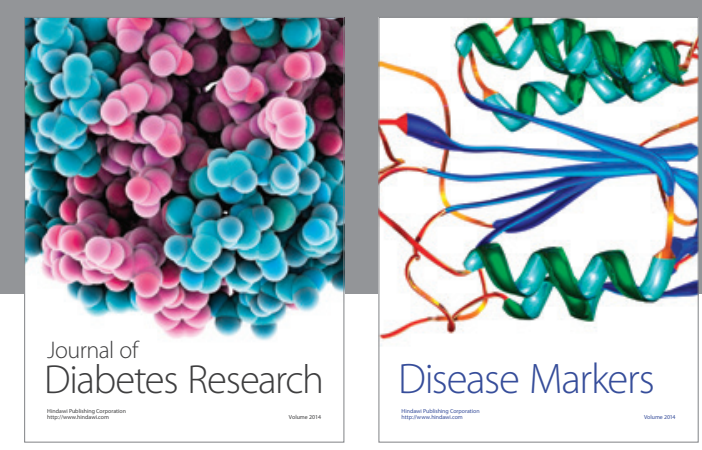

Disease Markers
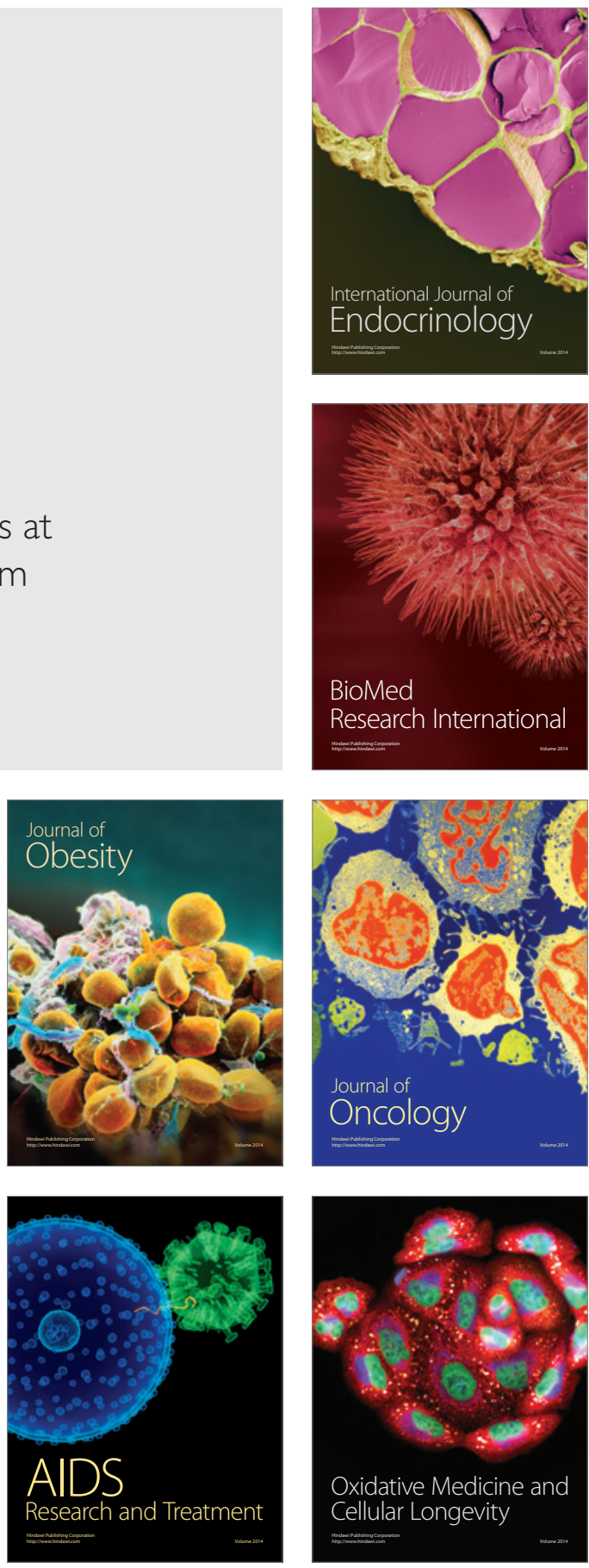